NBER WORKING PAPER SERIES

\title{
THE POLICY CONTEXT AND INFANT AND TODDLER CARE IN THE WELFARE REFORM ERA
}

\author{
Ann Dryden Witte \\ Magaly Queralt \\ Robert Witt \\ Harriet Griesinger \\ Working Paper 8893 \\ http://www.nber.org/papers/w8893
NATIONAL BUREAU OF ECONOMIC RESEARCH 1050 Massachusetts Avenue
Cambridge, MA 02138
April 2002

This paper is a product of the Wellesley Child Care Policy Research Partnership and of the Child Care Bureau's Child Care Policy Research Consortium. Our work was supported by Wellesley College under Grant \#90YE0006 from the Child Care Bureau, Administration for Children and Families (ACF), Department of Health and Human Services (DHHS). We are thankful to many people and organizations for their cooperation, feedback, and data. In particular, we wish to thank Ardith Wieworka, MA Commissioner of Child Care Services (OCCS,) Irene Taylor-Wooten, former Director of MDC Child Development Services (CDS) and Barbara Weinstein (President of Family Central) for their support, as well as Rod Southwick (OCCS,) Pilar Feldman (MDC Information Technology Department) and Anita Platt (R\&R Director of Family Central) for data and research direction. Finally, we wish to thank Pia Divine, Ivelisse Martinez-Beck, Martha Moorehouse, Elizabeth Peters and Karen Tvedt for their insightful comments on early drafts of this paper. The cooperation and support of our sponsors and of these individuals and organizations in no way indicates their concurrence with our analyses or conclusions. We alone are responsible for the views and opinions expressed in this paper and for all errors and omissions. The views expressed herein are those of the authors and not necessarily those of the National Bureau of Economic Research.

(C) 2002 by Ann Dryden Witte, Magaly Queralt, Robert Witt and Harriet Griesinger. All rights reserved. Short sections of text, not to exceed two paragraphs, may be quoted without explicit permission provided that full credit, including $(\mathrm{C}$ notice, is given to the source. 
The Policy Context and Infant and Toddler Care in the Welfare Reform Era Ann Dryden Witte, Magaly Queralt, Robert Witt and Harriet Griesinger

NBER Working Paper No. 8893

April 2002

JEL No. I38, H40, J22, I20

\begin{abstract}
We provide descriptive evidence from Miami-Dade County (MDC), FL and from five representative areas in Massachusetts (MA) that government policies governing welfare reform, the child-care subsidy system and minimum-standards regulation have had considerable impact on the availability, price, and quality of infant and toddler care, as welfare reform progressed from 1996 to 2000. Among our more interesting findings are the following: (1) There has been more than a doubling of the number of low-income infants and toddlers with child care subsidies in formal care in MDC, an area where cash assistance recipients are required to be active when their youngest child is three years old; and (2) Child care centers in both MA and MDC appear to be subsidizing their infant and toddler programs; this helps to explain why it has been difficult to expand the amount of infant and toddler care available.
\end{abstract}

Ann Witte

Department of Economics

Wellesley College

106 Central Street

Wellesley, MA 02481

and Wellesley Child Care Research Partnership

and NBER

awitte@wellesley.edu

Robert Witt

Department of Economics

University of Surrey

Guildford

Surrey

GU2 5XH

United Kingdom

and Wellesley Child Care Research Partnership

r.witt@surrey.ac.uk
Magaly Queralt

Wellesley Child Care Research Partnership

155 Ocean Lane Dr., Suite 812

Miami, FL 33149
Harriet Griesinger

Wellesley Child Care Research Partnership

23 Bellevue Ave

Cambridge, MA 02140

hgriesin@wellesley.edu 


\section{The Policy Context and Infant and Toddler Care in the Welfare Reform Era}

We provide descriptive evidence from Miami Dade County (MDC) in Florida (FL) and from five representative areas in Massachusetts (MA) that government policies governing welfare reform, the child-care subsidy system, and minimum-standards regulations have had considerable influence on the availability, price, and quality of infant and toddler care, as welfare reform progressed from 1996 to 2000 . We suspect that, in addition to the public policy environment, the very different situations for infant and toddler care in MDC and MA have been influenced by the markedly higher proportion of the population that is foreign born in MDC as well as by differences between MDC and MA in income and educational levels.

The period of our study, from February 1996 to March 2000, spans the period before and after welfare reform in FL (which started on October 1, 1996) and the period before and after December 1, 1996 (which is the date when MA imposed time limits on welfare recipients). During the period of our study, the budgets for child care subsidies expanded markedly in both MDC and MA.

The purpose of our study is two fold. First, we provide a description of how child care and the use of child care subsidies have changed as welfare reform has progressed. Second, we combine our descriptive results with information on the policy and socioeconomic context of our research sites to generate a number of hypotheses that we feel merit further study.

The outline of this paper is as follows. In the next section, we describe the data we use. The section that follows contains our findings regarding: (1) the use of child care subsidies, (2) the type of care, (3) the availability of care, (4) the quality of care and (5) the price of care. For each topic, we begin by describing our results and then we present the policy context related to the results. For selected results, we present hypotheses that we believe merit further investigation. The final section of the paper contains our conclusions.

\section{Data Sources}

For FL, we use data for Miami-Dade County (MDC). MDC, located in South FL, is FL's most populous county and contains approximately $40 \%$ of the state's welfare population. MDC has a population of 2,253,362-- 57\% Hispanic, 21\% non-Hispanic white, and 19\% black (US Bureau of the Census, 2001). Hispanics in MDC are predominantly Cuban, Nicaraguan, and Colombian. The non-Hispanic white population has been dwindling, particularly after Hurricane Andrew, in large part due to the arrival of continuous waves of immigrants from Latin America and the Caribbean. The black population is split between Afro-Americans and Caribbean blacks. Haitians are the poorest and largest segment of the county's Caribbean black population. MDC's poverty rate is unusually high, approximately 38\% among children (Queralt, Witte, \& Griesinger, 2000b).

For MDC, our main sources of data are: (1) provider records maintained by the two Resource and Referral (R\&R) agencies serving the county; (2) observational assessment records for providers receiving child care subsidies; (3) Gold Seal 
accreditation records, and (4) administrative records for families receiving child-care subsidies.

In MA, our study areas are: (1) the Boston metropolitan area, (2) the area west of Boston, from Lowell to Framingham, (3) Hampden County (Springfield, Chicopee, Holyoke and surrounding areas) and (4) the New Bedford/Fall River/Taunton area. See Lemke, Witte, Queralt and Witt (2000, page 32) for a list of MA townships included in our study sites. These areas were chosen by child care experts in the Massachusetts' Executive Office of Health and Human Services to be representative of the Commonwealth's population. In 2000, the population in MA was $84 \%$ non-Hispanic white, $6 \%$ Hispanic (of any race), 5\% black, and 4\% Asian. (U.S. Census, 2001). The poverty rate for children under age 18 in 1998 for the state was $13.8 \%$ (Bennett and Hsien-Hen Lu, 2000).

The MA data used in this study come from four sources: (1) provider records maintained by the five R\&R agencies serving our study areas, (2) monthly voucher billing files received from the Office of Child Care Services (OCCS), from which we obtained information on the use of and payments for child care subsidies, and (3) child care licensing list received from OCCS, from which we obtained data on capacities (slots).

The provider data we use contains information on all licensed centers and most license-exempt centers. Head Start providers are included in both the MA and MDC provider data. The coverage of family child care is more comprehensive in MA than in MDC for two reasons. First, licensing requirements for family child care are somewhat more stringent in MA than in MDC. ${ }^{1}$ Second, the available evidence indicates that there are many fewer underground family child care homes in MA than in MDC. ${ }^{2}$ The provider data does not contain information on informal providers, although the subsidy databases we use contain information on families that use child care subsidies to purchase informal care.

\section{Findings}

I. HOW HAS THE NUMBER OF INFANTS AND TODDLERS WITH CHILD CARE SUBSIDIES CHANGED DURING THE COURSE OF WELFARE REFORM?

\section{* FINDING: The number of infant and toddlers in formal care has increased during the course of welfare reform in both MA and MDC. Compared to MA, the increase in the number of infants and toddlers in subsidized care in MDC has been dramatic.}

As can be seen in Figure 1, the number of infants enrolled in subsidized child care in MDC grew markedly during the course of welfare reform. According to the records of

\footnotetext{
${ }^{1}$ MA requires anyone who cares for an unrelated child on a regular basis to be licensed while MDC requires licensure only if the provider cares for 2 or more unrelated children and receives pay for caring for at least one child.

${ }^{2}$ A study conducted for the Massachusetts Affordability Task Force (Marshall, et al., 1988) found few unlicensed family child care homes. Our work in MDC has uncovered numerous unlicensed family child care homes.
} 
the subsidy management agency, in March 1996, the beginning of our study period and six months prior to welfare reform, the number of infants from low-income families receiving care in MDC under the child-care subsidy program was slightly less than 400 . By March 2000, almost 1,000 infants were in subsidized child care. This represents an increase of almost $150 \%$. This increase in the number of infants from current and former cash assistance families receiving subsidized child care in MDC was particularly marked after September 1998, the date that families began to be dropped from cash assistance under FL's 24-month time limit. ${ }^{3}$

The number of one-year-olds receiving subsidized child care in MDC also grew rapidly during the period of welfare reform, although not as rapidly as the number of infants. In March 1996, the number of one-year-olds from low-income families receiving care under the child-care subsidy program was slightly less than 900. By March 2000, the record shows over 2,000 one-year-olds were in subsidized child care. This represents an increase of almost $125 \%$. As for infants, the growth in the number of one-year-olds from current and former cash assistance families receiving subsidized child care also increased markedly after September 1998, when FL's 24-month time limits began to kick in for some families.

The number of two-year-olds receiving subsidized child care in MDC approximately doubled between March 1996 and March 2000. In March 1996, the number of two-year-olds from low-income families receiving care under the child-care subsidy program was slightly over 1,100. By March 2000, almost 2,300 two-year-olds were in subsidized child care. As in the case of infants and one-year-olds, the number of two-year-olds in subsidized child care increased most rapidly after September 1998. However, the growth in enrollments of two-year-olds in subsidized care was somewhat less rapid than the enrollment of infants and one-year-olds. This may reflect the fact that, prior to welfare reform, cash assistance recipients in FL were already required to participate in the JOBS program when their youngest child was three years of age.

Table 1 shows the proportion of vouchers (i.e., child-care subsidies) used by families for infant enrollment in different types of child care. These data are derived from the monthly billing files of three representative Child Care Resource Agencies (CCRAs) ${ }^{4}$ for the month of May in 1997, 1998 and 1999. The number of infants from low-income families receiving care under the voucher program in these three areas in MA increased by 10 percent between 1997 and 1999, from 1157 to 1277. During this period, the proportion of infants in centers declined from $44 \%$ to $34 \%$, while the proportion of infants in informal care increased from $27 \%$ to $34 \%$.

\footnotetext{
${ }^{3}$ The increased use of child care subsidies is not the direct result of families losing their eligibility for cash assistance. Only approximately 1500 families statewide reached their 24-month time limit in September 1998 and only about 1000 families reached their 36-month time limit in October 1999. The increased use of child care subsidies in September 1998 probably results from the combined effects of increased activity requirements for cash assistance recipients, particularly recipients with young children, and accelerated departures from cash assistance as the 24-month and 36-month time limits became more salient. The latter effect is particularly likely because the local Miami-Dade Wages Coalition that managed welfare reform became fully operational and focused on moving cash assistance recipients from welfare to work during the summer and fall of 1998.

${ }^{4}$ The three CCRAs are Child Care Choices of Boston, New England Farm Workers Council in Hampden County, and Child Care Works, which serves the Fall River/New Bedford/Taunton area of the state. We were not able to use data for our other two study areas (the western suburbs of Boston) and the Lowell/Framingham areas because of a redefinition of their service boundaries.
} 
The proportion of vouchers issued by the same three CCRAs in MA and used by families for toddler care increased somewhat more rapidly than the number of infants receiving care under the voucher program (12\% instead of $10 \%)$. Around $45 \%$ of the vouchers for toddler care went to centers and $20 \%$ to informal caregivers. The percent of vouchers for the care of infants and toddlers in MA going to family child-care homes remained approximately the same throughout this period.

\section{Policy Context}

(1) Welfare Reform

For the purpose of understanding the change in the numbers of infants and toddlers with child-care subsidies, two aspects of FL's welfare reform are particularly important. First, adults receiving cash assistance are required to be active when their youngest child is three months of age. Second, FL's time limits for cash assistance are stringent. The time limit for most recipients is 24 months in any 5 -year period and a lifetime limit of 48 months of cash assistance. ${ }^{5}$ Given that welfare reform started in FL in October 1996, these time limits began to kick in for some recipients after September 1998.

The implementation of welfare reform in FL was associated with a dramatic increase in funding for child-care subsidies and, to a lesser extent, for other early childhood education programs, such as Head Start, Early Head Start, and public-school pre-kindergarten programs. During our study period, the budget for child-care subsidies in FL rose from $\$ 180$ million in July 1995 to almost $\$ 450$ million in July $1999 .^{6}$ This increased funding for child care and early childhood programs was largely for the purpose of enabling poor and low-income parents to move from welfare to work and to maintain independence from the welfare system through employment.

In April 1995, the Commonwealth of Massachusetts requested a welfare reform waiver from the federal government. MA's plan included job training, a work requirement, time limits, medical assistance, and centralization of the public assistance system. The waiver was granted, except for the time limits. Overseen by the newly formed Department of Transitional Assistance (replacing the MA Department of Public Welfare as of July 1, 1995), these reforms, with the exception of time limits, were initiated on November 1, 1995. After federal welfare reform, MA's previously requested time limits were implemented, as they became required for federal funding. Cash assistance recipients in MA became subject to time limits beginning on December 1, 1996.

In MA, anyone subject to the time limits is permitted to receive Transitional Assistance for Families with Dependent Children funds (TAFDC, as the TANF program is referred to in MA) for a maximum of 24 months in any consecutive 60 months. Anyone subject to work requirements must, within 60 days of receiving TAFDC funds, be actively involved in some type of work for at least 20 hours per week. If the person fails to find a job, $\mathrm{s} /$ he is required to perform 20 hours of community service per week. A TAFDC recipient is exempt from the time limits and from the work requirement if her/his

${ }^{5}$ Long-term welfare recipients (i.e., those who received AFDC for 36 of the last 60 months prior to welfare reform) have a limit of 36 months of cash assistance in a 72-month period. They also have a lifetime limit of 48 months of cash assistance.

${ }^{6}$ Additional funds for child-care subsidies came from local match (either cash or in-kind contributions), which is required in order to demonstrate local commitment to the subsidized child-care program. 
youngest child is under the age of two. The recipient remains work exempt, however, until the youngest child is six years old. It is important to note that these are separate requirements. If a person receives benefits while her/his youngest child is two and three years old, thus exhausting the time limits, the time limit deadline comes into effect and benefits are terminated, even though the recipient would otherwise remain classified as work exempt for the next two years while the youngest child passes through the ages of four and five.

Spending on child-care subsidies in MA increased from $\$ 180$ million in Fiscal Year (FY) 1996 (July1, 1995 to June 30, 1996) to \$316 million in FY 2000. However, welfare reform in MA did not generate an influx of infants and toddlers from low-income families into child care. This was not unintended. As detailed below, child care for infants and toddlers is very costly in MA.

(2) The Subsidized Child Care Program

\section{Eligibility}

FL law prescribes that every child younger than age 13 in an eligible family (i.e., a family with income below $150 \%$ of the Federal Poverty Level [FPL]) may receive subsidized child care. In 1999 the maximum eligible income for a family of 3 was $\$ 20,082$. Child-care subsidies were an entitlement for active cash assistance recipients and for those income-eligible recipients leaving the cash assistance program prior to welfare reform. However, since the implementation of welfare reform on October 1, 1996, child-care subsidies are made available in FL only if resources are available. Child-care subsidies in MDC are allocated on the basis of state established priorities for participation, which favor children at risk of abuse and neglect, the children of cash assistance recipients, and the children of families transitioning off cash assistance. ${ }^{7}$ FL's Transitional Child Care (TCC) program offers child care to working former cash assistance recipients eligible for child-care services for up to 2 years after the family leaves cash assistance. Low-income families that do not receive cash assistance and that are not eligible for TCC, called Income-Eligible families, have lower priority for subsidy receipt. However, during the period of our study the rapid increase in funding meant that waiting lists for subsidies for infants and toddlers were small. ${ }^{8}$

According to MA's law, in 1999 all families with children under the age of 13 with incomes below $\$ 23,172,167 \%$ of FPL, could obtain child-care subsidies, to the extent that funds are available. To facilitate welfare reform, MA has offered child-care vouchers to all active recipients of cash assistance. MA also has provided one year of

${ }^{7}$ In July 1996, FL set the following priorities for participation in the subsidized child care program: (1) children at risk of abuse, neglect, or exploitation; (2) children of participants in the WAGES program and those transitioning off WAGES, (3) children of migrant farm workers, (4) children of teen parents, (5) children from other families at risk of welfare dependency due to a family income of less than 100 percent of the (FPL); and (6) children of working families whose family income is equal to or greater than 100 percent but does not exceed 150 percent of the FPL. In order to further facilitate welfare reform, the FL Legislature, on July 1, 1997, split the budget for the two main subsidized child-care programs. One part of the budget was set aside for child-care subsidies for current and former welfare recipients. The other part was designated for families at risk of welfare dependency and other working families eligible on the basis of low-income. These latter programs are referred to in FL as "Income-Eligible" child care.

${ }^{8}$ The child-care subsidy administration files in MDC show limited numbers of infants and toddlers waiting for care. The January 2001 files, for example, show 27 infants, 37 one-year-olds, and 40 two-yearolds from income-eligible families and 56 infants, 58 one-year-olds, and 68 one-year-olds from families receiving cash assistance waiting for care. 
Transitional Child Care assistance (TCC) to those who leave cash assistance. In the interest of providing continuing care, MA has also made child care subsidies available to former cash assistance recipients after they exhaust their TCC benefits for as long as they are income eligible.

Child-care subsidies in MA are available to income-eligible low-income families that are not current or former cash assistance recipients only to the degree that funds are available. Detailed information for these state contracted slots was not available. However, throughout our study period, MA had a substantial waiting list for IncomeEligible child-care subsidies. In November 2000, for example, there were 2412 infants and 3602 toddlers (among children of other ages) from Income-Eligible families on the waiting list.

$>$ HYPOTHESIS: The number of infants and toddlers receiving child-care subsidies will depend on state regulations governing the age (of the children) at which parents must be active under welfare reform and the budget for child-care subsidies.

\section{WHO CARES FOR CHILDREN WITH CHILD CARE SUBSIDIES?}

* FINDING: In MDC the majority of providers serving infants and toddlers are centers, whereas in MA, family child care homes are the predominant providers serving infants and toddlers.

\section{* FINDING: Family child care homes are far more likely to participate in the subsidized child-care program in MA than in MDC.}

As noted in Queralt, Witte \& Griesinger (2000a), centers constitute a much larger proportion of the provider community in MDC than in other areas of FL or the US. Throughout our study period, centers comprised almost $50 \%$ of the providers in MDC. By way of contrast, centers comprised less than $20 \%$ of the providers in MA (Witt, et al., 2000).

Figure 2 shows that over $80 \%$ of the providers participating in the subsidized child care program and serving infants in MDC are centers; however, only 53\% of the providers serving infants but not participating in the subsidy program are centers. In contrast, in both the subsidized and unsubsidized sectors in MA, over $80 \%$ of the providers serving infants are family child care homes.

Similarly, we found that $80 \%$ of the providers serving toddlers and participating in the child care subsidy program in MDC are centers, while only $65 \%$ of the providers serving toddlers but not participating in the subsidy program are centers. In contrast, in MA over $80 \%$ of the providers (subsidized and unsubsidized) serving toddlers are family child care homes.

Information for both infant and toddler programs makes clear that family child care homes are far more likely to participate in the subsidized child-care program in MA than in MDC. One reason for this striking difference may be that MA has overcome the added administrative costs of dealing with small providers that enter and exit the market frequently, such as family child care homes, by establishing family child care networks. 
These networks deal with the subsidy agencies, recruit new homes, and handle the administrative tasks for a group of family child care homes.

\section{Policy Context}

In Florida, child-care providers may choose to enter into an agreement or contract with the child-care subsidy agency to take clients receiving subsidies. The contracted providers are required to accept subsidized children, but they are not guaranteed that any subsidized children will enroll. The subsidy management agencies refer child-care subsidy recipients who ask for help in locating care to those providers who have entered into contracts with the agency. Subsidy clients can select a provider from the list of contracted providers or they can elect to receive a voucher that can be used at any provider or to purchase informal care.

During the period covered by the MDC data (February 1996 to March 2000), 95\% of the child care subsidies (i.e., vouchers) issued in MDC were used to purchase care from providers with purchase-of-service contracts with the subsidy management agency. The remaining child care subsidies $(5 \%)$ were used to pay non-contracted providers. Ninety-nine percent of the child care subsidies issued to pay non-contracted providers were used for informal care. We surmise that at the time of our study parents mostly used contracted providers largely because, when using contracted providers, they were only responsible for the co-payment and for any late fees or transportation fees. In contrast, use of vouchers to pay for care by non-contracted providers required parents to pay the full price of care in order to be reimbursed at the end of the month. This system was changed in $2000 .^{9}$

MA operates a "mixed" child care subsidy system that provides current and former cash assistance recipients with vouchers and Income-Eligible children with "slots" purchased directly by the state from selected licensed providers. As operated during our study period, the MA voucher program provided families with greater choice than MDC's purchase of service contract system.

$>$ HYPOTHESIS: The way in which the child-care subsidy system is administered can greatly affect the type of care that is purchased by the system.

\section{WHAT HAS HAPPENED TO THE AVAILABILITY OF CARE}

* FINDING: The large and rapid increase in the full-time center enrollment of subsidized infants and toddlers after September 1998 in MDC may have displaced some infants and toddler without access to child care subsidies.

* FINDING: The growth in the full-time enrollment of infants and toddlers at subsidized centers in MDC has been far less dramatic than the increase in the number of child care subsidies for infant and toddler care issued by child-care subsidy agencies.

\footnotetext{
${ }^{9}$ Under the new system established in early 2000, parents are no longer required to pay for care up front to be reimbursed. The payment for care now goes directly to the provider receiving the voucher, just as it does for providers with contracts.
} 
Figure 3 summarizes the total slots available (capacities), enrollments, and vacancies reported to the R\&Rs by MDC child care providers who were serving infants for the period spanning February 1996 to March 1999. As can be seen, enrollments at providers serving infants and accepting child care subsidies (i.e., vouchers) started to increase in February 1998. By the end of our study period (March 1999), enrollments at such providers had increased $11 \%$. Note also that the vacancies reported by providers accepting subsidies began to decline in late 1997. In contrast, Figure 3 shows that enrollments at providers serving infants but not accepting child care subsidies (i.e., no vouchers) declined slightly during the period.

Figure 4 shows that full-time infant (i.e., age $<12$ months) enrollments at centers accepting vouchers, as reported by center providers to the R\&Rs, increased slightly during the study period, from about 1,000 infants at the beginning of the period to 1,150 at the end of the period, an increase of $15 \%$. Conversely, during the same period, fulltime infant enrollments at centers not accepting vouchers declined from about 1,160 to $1,000 .^{10}$

It is interesting that, as reported by center providers, the growth in full-time infant enrollments at subsidized centers is far less dramatic than the over $150 \%$ increase in the number of child care subsidies issued by the child-care subsidy agencies in MDC for infant care (see Figure 1). Specifically, the number of vouchers issued for infant care increased from approximately 400 to almost 1,000 between February 1996 and March 1999. There are a number of possible explanations for this discrepancy. For example, it is possible that many vouchers for infant care were for part-time care. ${ }^{11}$ It is also possible that infants with child-care subsidies increasingly displaced other infants without subsidies. The fact that the full-time enrollment of infants at providers with subsidies increased while the enrollment of infants at unsubsidized providers declined provides some support for the displacement hypothesis. It is also possible, particularly for the income-eligible group, that families formerly paying the full cost of care are now receiving subsidies.

Figure 4 also shows that, over the study period, the number of one-year-olds and two-year olds in full-time care at subsidized providers increased at rates of $17 \%$ and $13 \%$, respectively. In contrast, enrollment of one-year-olds and two-year-olds in full-time care at unsubsidized providers decreased by a similar amount.

$>$ HYPOTHESIS: Large influxes of subsidized infants and toddlers into formal child care can, at least in the short term, displace unsubsidized children.

\section{WHAT HAS HAPPENED TO THE QUALITY OF CARE?}

Quality child care and early education fosters children's intellectual, social, and

\footnotetext{
${ }^{10}$ The reader should note that these enrollment-by-age figures reported by providers to the MDC R\&Rs are not considered to be as reliable as the overall enrollments they report.

${ }^{11}$ Not all individuals receiving child-care subsidies were working on a full-time basis. For example, during our study period, only $30 \%$ of cash assistance recipients with subsidies were working and among those working only $23 \%$ worked 20 or more hours per week. However, $93 \%$ of those receiving Transitional Child Care Assistance (TCC) were working (88\% of those in this group were working at least 20 hours per week) and $99 \%$ of Income-Eligible subsidy clients were working (95\% of those in this group were working at least 20 hours per week).
} 
emotional development, gets them ready for school, and puts them on the right path toward healthy and productive citizenship. ${ }^{12}$ Providing quality care makes good economic sense. Specifically, early intervention has been shown to reduce later public expenditures for special education, grade repetitions, public assistance payments, delinquency and crime. See Vandell and Wolfe (2000) for a recent survey of the literature on the impact of quality care on child development.

Our study examines quality on the basis of several structural measures derived from the provider records maintained by the R\&R agencies in FL and MA. In addition, for providers participating in the subsidized child care program in MDC we obtain structural and process quality ratings from the Child Care Program Assessments. No outcome measures were available from any source.

* FINDING: During the course of welfare reform in MDC, the range in the educational attainment of staff at subsidized centers offering care for infants and toddlers has been widening. Specifically, we observe an increase in the proportion of staff with less than a high school education as well as an increase in the proportion of staff with $A A$ and $B A$ degrees.

* FINDING: Staff at subsidized centers offering infant or toddler care in MDC are significantly less likely to have a high school diploma than staff at unsubsidized facilities.

* FINDING: Staff at subsidized centers in MDC offering toddler care, as compared to the staff at unsubsidized centers, are significantly less likely to have an AA or BA degree.

* FINDING: In MA family child care providers who do not take child care vouchers and who are serving infants and toddlers are more likely to have a BA degree than those who accept vouchers.

One recognized aspect of quality in the child care and early childhood education world is the educational level of the staff. We obtain information on the academic

12 There are three important aspects of quality child care--structural, process, and outcome. The Early Childhood Education community refers to structural quality as the quality of the resources or inputs used in the production of child care services. These are generally observable and measurable and relatively easy to regulate by licensing bodies. They include such things as caregiver-to-child ratios, group sizes, and education and training of the staff. Process quality refers to the quality of the social environment and social relations between teachers or caregivers and children, the emotional tone of the classroom, the level of stimulation children receive, and the quality of the activities in which children engage while in care. These things are best measured by direct observation. Outcome quality refers to the effects of the care received by children in terms of developmental outcomes such as ability to understand and use language, preacademic skills such as ability to count and recognize letters, later academic performance, and presence or absence of problem behaviors such as aggression, dependency, sad or angry feelings, and so on. To measure outcome quality it is necessary to follow up children over a period of time. 
credentials of child-care staff at centers with infant and toddler programs in MDC from the R\&R databases.

Staff employed at subsidized centers with infant programs are somewhat less likely to have a high school diploma than the staff employed by other providers in MDC. Specifically, an average of $88 \%$ of the staff at subsidized centers with infant programs have a high school diploma or higher credentials, compared to an average of $89 \%$ of the staff at centers that do not participate in the child care subsidy program. While this difference is small, it is statistically significant ( $p$-value $=.005$ ). Over the four-year period of our study, the average percent of staff with a high school education at subsidized providers decreased slightly.

For centers with infant programs in MDC, there is no significant difference in the average proportion of staff with AAs or BAs between providers participating in the subsidized child care program and those that do not participate. The percent of staff with an AA degree increased from approximately $36 \%$ at the beginning of our study period to $39 \%$ at the end of our study period. Similarly, the percent of staff with BAs increased from $11 \%$ at the beginning of the period to $13 \%$ at the end of the period.

Staff employed at centers with toddler programs and participating in the subsidized child care program in MDC are less likely to have a high school diploma, an AA degree or a BA degree than the staff employed by other providers in MDC. To be more specific, on average, $88 \%$ of the staff at centers with toddler programs participating in the subsidized child care program have a high school diploma, 35\% have an AA and $10 \%$ have a BA. By way of contrast, on average, $91 \%$ of the staff at centers with toddler programs and not participating in the subsidized child care program have a high school diploma, 38\% have an AA and 12\% have a BA. The difference in educational credentials between centers that enroll toddlers and participate in the subsidized child care program and those that do not participate is statistically significant. ${ }^{13}$ As for infant programs in MDC, the proportion of staff with a high school diploma at centers with toddler programs declined slightly during the period of our study, while the proportion of staff with AA and BA increased slightly.

We have no information on the credentials of staff at child care centers in MA because such data are not collected by R\&Rs in Massachusetts. The only information available in the MA R\&R records during our study period is for family child care providers. Somewhat less than $7 \%$ of family child care providers (in our sample) caring for infants and toddlers in MA had AA degrees in 1999. Providers that take child care vouchers were less likely to have an AA than those who did not. However, the difference in the percent with an AA degree in the two groups is not statistically significantly. Providers serving infants and toddlers who did not accept vouchers were much more likely to have BAs than those who did throughout our study period. To be more explicit, $13 \%$ of providers who served infants and who did not accept vouchers and $14 \%$ of providers who served toddlers and who did not accept vouchers had BAs, while only 5\% of providers that served infant and toddlers and who accepted vouchers had BA. The differences in the proportion of providers with BAs are statistically significant.

The proportion of family providers with college degrees in MA is approximately the same as the proportion of center staff with college degrees in MDC. The unusually

${ }^{13}$ The $\mathrm{p}$-value for each of the tests for significant differences in average credentials is 0.00 . 
high proportion of family providers with BAs in MA is likely related to the higher overall educational level of the population in MA, as compared to MDC.

$>$ HYPOTHESIS: On average, providers participating in the child care subsidy program will have lower educational levels than providers that do not participate in the child care subsidy program.

\section{* FINDING: Less than 3\% of the child care and early education facilities serving infants and toddlers in MDC were accredited. In contrast, of the facilities serving infants and toddlers in MA, at least $30 \%$ of the centers accepting child-care vouchers and over $\mathbf{2 0 \%}$ of those that do not them were accredited.}

Accreditation by a nationally recognized professional organization is widely recognized in the child-care field as an indicator of quality. This is because, to be accredited and re-accredited by a nationally recognized organization such as the National Association for the Education of Young Children (NAEYC), a child care facility must pass periodic and extensive reviews of all aspects of its program.

We found that only a very small fraction of the child care and early childhood education facilities serving infants or toddlers in MDC were accredited during the 38month period of our study. Two percent of centers that were not participating in the subsidized child care program and that were offering infant care (a total of 4 of 196 providers) were accredited in February 1996, compared to $1.5 \%$ of centers offering infant care and participating in the subsidized child care program (a total of 3 of 196 providers). By March 1999, an additional provider in both the subsidized and unsubsidized sectors had become accredited. However, the level of accreditation in both sectors remained strikingly low. ${ }^{14}$ Unsubsidized center providers serving toddlers were more likely to be accredited (i.e., approximately 3\% at both the beginning and end of our study period). However, subsidized center providers serving toddlers were no more likely to be accredited than those serving infants.

It is interesting to note that, for the period of our study, the majority of accredited facilities in MDC were run by religious organizations (e.g., Christian [nondenominational], Jewish, Congregational, Catholic, Lutheran, Presbyterian), including a number of accredited facilities run by various religious charities in poor neighborhoods; several of the accredited facilities were Head Start programs; and several were employer run (e.g., Florida Power and Light and Ryder Corporation). Many accredited facilities were in areas with large numbers of migrant farm workers (for example, Homestead or Florida City). The number of private, non-religious, accredited providers in MDC was minimal as of the end of our study period in March 1999.

The percent of nationally accredited child care and early education facilities in MDC is unusually small for a major metropolitan area. In contrast, in the five representative areas of MA we studied and during the period of our study, $32 \%$ of centers with infant programs and accepting vouchers were accredited, as well as $21 \%$ of centers

\footnotetext{
${ }^{14}$ For our analysis of the accreditation situation, we used Gold Seal program records going back to the inception of this program in 1996. These records were kept by the state's R\&R Network (The Florida Children's Forum). We also used the on-line NAEYC records (National Academy of Early Childhood Programs, 2000).
} 
with infant programs that did not accept vouchers. The rate of accreditation for toddler programs in MA (30\% for programs accepting vouchers and $25 \%$ for those not accepting vouchers) was also reasonably high.

Policy Context

In FL, under the Gold Seal Quality Care program established on July 1, 1996, providers accredited by a nationally recognized accrediting association whose standards substantially meet or exceed those of the National Association for the Education of Young Children (NAEYC), the National Association for Family Child Care, or the National Early Childhood Program Accreditation Commission are designated as Gold Seal providers. Beginning in July 1, 1998, Gold Seal providers have been paid up to 20\% higher reimbursements for providing subsidized child care, as long as this rate does not exceed their private pay rate. ${ }^{15}$ During the period of our study, MA did not provide financial incentives for accreditation. However, providers were required to be accredited or to have applied for accreditation in order to participate in the MA Department of Education Community Partnership for Children (CPC) program, which provides substantial amounts of funding for the care of 3- and 4-year-old children.

Given the policy context in MA and MDC, one might reasonably expect higher levels of accreditation, particularly for subsidized providers, in MDC than in MA. Yet we find the reverse. Why?

$>$ HYPOTHESIS: MA has a substantially higher proportion of accredited child-care centers than MDC because of substantially higher market prices for care and substantially higher reimbursement rates.

Supporting information: As will be described in greater detail below, prices for infant and toddler care in MDC are substantially lower (even after accounting for differences in child-care regulations and in the cost of living) in MDC than in MA (see Tables 2 and 3). In part reflecting market prices, reimbursement rates for infant and toddler care in MDC are substantially below the reimbursement rates for infant and toddler care in MA. For example, in the fall of 1998, the weekly reimbursement rate for full-time center care of children less than 12 months old was $\$ 95$ in MDC, $\$ 182.50$ in Western MA and \$225 in the Boston area.

The subsidy management agencies in MDC have found that many providers wishing to become Gold Seal providers are unable, for financial reasons, to make the needed changes in staff, facilities, resources, and programs. To overcome the financial barriers, the Miami Dade School Readiness Coalition, with child care quality enhancement funds from the state, recently has begun to award a limited number of grants to providers wishing to upgrade in order to achieve Gold Seal status.

Becoming accredited, which may take two years or even more time to achieve (in the case of accreditation by NAEYC) requires that providers make considerable investments in improving their facility and the credentials of their staff. As facilities increase quality, they must be able to charge higher prices or obtain grants to cover their increased costs. Raising the price of care is hard, given the low median income and high level of poverty of families with children in MDC.

${ }^{15}$ Beginning in February 2000, the private pay ceiling was relaxed for Gold Seal providers in FL, so that they currently need to have only $5 \%$ of their private clients paying top price in order to qualify for the pay differential. 
Hypothesis: MA has a substantially higher proportion of centers accredited than MDC because the proportion of the MA population that is native born is higher and the level of income and education of the population is higher.

Supporting information: The proportion of the population that is native born was almost $90 \%$ in MA in 1999 , while only $55 \%$ of the population was native born in MDC in 1990. Conservative estimates place the proportion of the population that is native born in MDC today at less than $40 \%{ }^{16}$

Using data from the March 2000 Current Population Survey, the Census Bureau estimates that $85 \%$ of MA residents had completed high school and $33 \%$ had BAs or higher degrees. The estimated proportion of the populations with high school degrees in MDC in March 2000 was $75 \%$ and the proportion of the population with a BA or higher degrees was $23 \%$. The Census Bureau estimates that the median household income in MA in 1997 was $\$ 43,015$ while the estimated median household income in MDC was $\$ 30,000$. Sixteen percent of young children in MA live in poverty while $38 \%$ of young children in MDC live in poverty.

\section{* FINDING: In MDC, center-based infant and toddler programs that accept children with child care subsidies rely heavily on the CDA credential for their staff, while those that do not accept children with subsidies place less reliance on the CDA and more on formal education, such as a high school diploma, AA or BA degree.}

\section{* FINDING: In MA, family child care providers are more likely to have an $A A$ or a $B A$ than a CDA.}

Centers with infant programs in MDC and participating in the subsidized child care program have a higher percent of their staff with the CDA credential (on average, over $50 \%$ ) than do centers with infant programs that do not participate (on average, $40 \%$ ). The difference in the average percent of staff with CDA in the two groups is statistically significant ( $\mathrm{p}$-value $=0.00)$. Centers with toddler programs and participating in the subsidized child care program in MDC also have a higher percent of staff with CDAs (an average of $52 \%$ with CDAs) than centers with toddler programs that do not participate (an average of $43 \%$ with CDAs).

During the period of our study less than $20 \%$ of providers in MDC reported to the $R \& R$ that their staff had the 30-hours of training required by FL's minimum standards regulation. Given the limited proportion of staff at centers with infant or toddler programs in MDC reporting compliance with the 30 -hour training requirement, one may infer that either this information is not consistently gathered by the R\&R or the requirement is not as actively enforced as the CDA requirement.

We have no information on the CDA credentials of staff at child care centers in MA because such data is not collected by MA R\&Rs. However, few family child care providers in MA have the CDA. This is not too surprising since MA law does not require

\footnotetext{
${ }^{16}$ This estimate considers only the 297,531 new legal immigrants reflected in INS statistics through 1998.
} 
the CDA but rather, as described below, accepts a reasonably wide range of early childhood education and training.

\section{Policy Context}

Beginning on July 1, 1996, the FL law requires that for every 20 preschool children enrolled in a licensed child-care facility operating 8 hours or more per week, one of the child-care personnel in the facility must have a Child Development Associate (CDA) credential or an educational credential that is equivalent or greater. ${ }^{17} \mathrm{FL}$ also requires that all child-care personnel hired on or after October 1, 1992 and all operators of family day care homes take an approved 30-clock-hour introductory course in child care. $^{18}$

Effective October 16, 1996, MA law requires that lead teachers for infants and toddlers be at least 21 years of age and fulfill certain minimum education, training and experience requirements. A number of different training/education/experience combinations can meet the requirements. For example, either of the following combinations would qualify: (1) a high school diploma or equivalent plus 12 college credits including credits in infant and toddler care plus 36 months of work experience, or (2) a BA or advanced degree in early education plus 12 college credits in infant and toddler care and 9 months of work experience.

$>$ HYPOTHESIS: The education and training observed at child care centers will be heavily influenced by minimum standards regarding the education/training/experience of child care staff.

$>$ HYPOTHESIS: Minimum standards that are not enforced will be violated.

\section{* FINDING: In MDC, subsidized centers serving infants or toddler are more likely than unsubsidized centers to report that they have a child development program.}

Recent research has shown the importance of child development activities for infants and toddlers. See National Research Council and Institute of Medicine (2000) for a recent survey of the literature. Children who receive primarily custodial care often develop developmental deficits that are difficult to overcome in subsequent years.

We looked at the proportion of centers with infant programs in MDC that report to the R\&R that they offer a child development program. Over $70 \%$ of centers with infant programs and participating in the subsidized child care program indicate that they have child development programs, while only $63 \%$ of non-participating centers with infant programs indicate that they have a child development program. The difference in the average percent of programs indicating that they have a child development program is statistically significant ( $\mathrm{p}$-value $=0.00$ ). It is interesting to note that, over the study period, the proportion of centers with infant programs that indicate that they have a child development program increases more substantially for programs that do not participate in

\footnotetext{
${ }^{17}$ The CDA may be the national credential or a state-approved CDA equivalency. Personnel with equivalent or higher formal educational credentials can be counted as meeting this requirement.

${ }^{18}$ Those in continuous employment since before October 1, 1992 are allowed to go by the previous child care training requirement of 20 hours.
} 
the subsidized child care program than for those that participate, but they remain consistently below the levels for subsidized programs. The situation for centers in MDC with toddler programs is similar.

- FINDING: Below-standard "generic" observational assessment scores at facilities offering infant and toddler care in MDC have approximately doubled (from 5\% of programs in 1996 to $11 \%$ of programs in 1999) during the course of welfare reform.

* FINDING: From January 1997 to March 1999 in MDC, among providers participating in the subsidized child care program, 20 infant programs, 17 toddler programs, and 24 programs serving two-year-olds received below-standard observational assessment scores.

We examined the assessment scores given to child-care providers participating in the subsidized child care program in MDC from January 1997 to March 1999. On average, providers received high ratings and, over the $2 \frac{1}{4}$ years covered by our data, provider "generic" ratings (i.e., ratings of program management, staff development and resources, group sizes, and parent involvement) increased slightly. However, the scores for programs serving infants and two-year-olds decreased and scores received by programs serving one-year old children remained essentially unchanged.

Consistent with overall county standards, we considered any programs with a score below $80 \%$ on the Infant Program, One-Year-Old Program, Two-Year-Old Program or Generic Program assessment to be below standard. During the period of our study, 20 infant programs, 17 toddler programs, and 24 programs serving two-year-olds received below-standard scores. ${ }^{19}$ The proportion of infant and toddler programs and the proportion of facilities serving infants and toddlers that received below-standard generic ratings increased during the period we consider. Specifically, in 1997, 5\% of the centers with infant programs received below-standard generic ratings, whereas in 1998 and in the first quarter of $199911 \%$ of the programs did so. Six percent of the toddler programs received below standard generic ratings in 1997, while 11\% did so in 1998 and in the first quarter of 1999.

${ }^{19}$ It should be understood that it is possible for a given facility to pass the observational assessment with an overall score of 80 or better, even though some of the age-group programs may get below-standard ratings. 


\section{Policy Context}

Florida's child care law prescribes that agencies in charge of administering the CCDF-subsidized child care program can enter into a service contract only with providers that achieve an overall score of at least $70 \%$ on the Child Care Program Assessment. (Beginning on July 1, 1998, MDC raised the minimum acceptable score to $80 \%$.) Once a provider is cited for non-compliance and is given an evaluation stating specific deficiencies, the provider must bring the program into compliance within 90 days. If the provider fails to achieve compliance within 90 days, the department must withhold any further payment.

Six different assessment tools are used for the Child Care Program Assessment. The "generic" tool covers areas such as program management, staff development and resources, group sizes, and parent involvement. The other five tools used are for each age group in care (i.e., infant, toddler, two-year-old, preschool, and school-age) and cover things such as physical environment (indoor and outdoor), learning environment, staff/child interaction, developmental program, parent involvement, health, and nutrition. (Copies of the assessment tools are included in the Appendix to Queralt, et al., 2000).

> HYPOTHESIS: A substantial influx of infants and toddlers into care can lead to a decline in the quality of care at providers with infant and toddler programs.

\section{WHAT PRICES ARE CHARGED FOR INFANT AND TODDLER CARE? \\ * FINDING: Prices for infant and toddler care in MA are more than $21 / 2$ times the equivalent prices in MDC.}

Table 2 provides descriptive statistics for the prices of infant and toddler care reported in the R\&R databases in the five study areas in MA for the period 1997-1999. Table 3 provides prices for similar types of care in MDC for the same period of time. The median full-time price of infant care during this period across the five areas in MA was \$218 per week for providers participating in the voucher program and \$234 per week for providers not participating. By way of contrast, the median price of infant care in MDC was $\$ 85$ per week for provider participating in the child care subsidy program and $\$ 75$ per week for providers that did not participate.

In MA the median weekly full-time price of toddler care was $\$ 194$ for providers participating in the voucher program and $\$ 214$ for non-participating providers. For toddler care as for infant care, prices in MDC are substantially less than half those in the five MA areas. See Table 2 and Table 3.

In MA, prices charged by providers that do not accept children with child-care vouchers are significantly higher than prices charged by providers that accept vouchers. The situation in MDC is the reverse, that is, prices charged by providers participating in the child care subsidy program are significantly higher than the prices charged by providers that do not participate.

\section{Policy Context}

FL and MA, like most states, require that centers maintain certain minimum caregiver-to-child ratios. Minimum standards regarding caregiver-to-child ratios and group sizes are likely to have substantial impacts on prices. States have set these minimum standards because of a large literature that indicates that lower caregiver-to- 
child ratios are associated with higher quality care. See Vandell and Wolfe, 2000 for a survey of this literature. The establishment and enforcement of minimum standards require political support. Thus, public demand for higher quality and safer and healthier care for children is generally reflected in more stringent standards for care.

In FL, the state sets minimum caregiver-to-child ratios for different age levels to be maintained by centers. For infants (under the age of 1 year), the minimum caregiver-tochild ratio is 1-to-4, for one-year old children it is 1-to-6, and for two-year olds it is 1-to11. FL does not regulate group sizes.

Like FL, MA sets minimum caregiver-to-child ratios that a center must maintain. MA's minimum standards are more stringent than FL's, particularly for toddlers. This is one indication that demand for quality child care is higher in MA than in FL. The minimum caregiver-to-child ratio for infants (ages 1 to 15 months) in MA is 1-to-3 and the minimum ratio for toddlers (ages 15 to 33 months) is 1-to-4. The Commonwealth also sets maximum group sizes. Specifically, there can be no more than 7 children in an infant group and 9 children in a toddler group.

$>$ HYPOTHESIS: Market prices for child care will reflect the costs of providing care (i.e., the supply side) as well as the demand for care in local child-care markets.

Supporting Information: The median price of infant and toddler care in MA is more than $2 \frac{1}{2}$ times the median price of infant and toddler care in MDC. The cost of labor and other items needed to provide child care is between $10 \%$ and $34 \%$ higher in MA than in MDC. ${ }^{20}$ MA's more stringent minimum-standard requirements mean that centers providing infant care in MA will have labor costs that are $32 \%$ higher than centers providing infant care in MDC. Minimum standards cause labor costs that are $50 \%$ higher in MA than in MDC for children between 15 and 24 months old and labor costs that are $275 \%$ higher for children 24 months to 33 months old.

We conclude that the costs of meeting higher minimum standards account for most of the observed difference in the price of care for 24 to 33 month old children in MA and MDC, but only partially explain the differences in prices charged for the care of children less than two-years old. Consequently, demand-side influences must account for much of the remaining price differences observed between MA and MDC with respect to the care of infants and one-year olds. The existing literature suggests that the income and educational levels of the population are strongly related to the demand for higher-quality child care. See Vandell and Wolfe (2000) for a survey of this literature. The much higher educational and income levels reported earlier for MA, as compared to MDC, are likely to account for much of the remaining price difference (after adjustment for cost) between MA and MDC with respect to the care of infants and one-year-olds.

\section{* FINDING: Both the median and 75th percentile of the prices charged by subsidized providers tend to converge to the maximum allowed state reimbursement rate. This type of price}

\footnotetext{
${ }^{20}$ For example the overall cost of living is $34 \%$ higher in Boston than in MDC and the cost of living in the western part of MA is $10 \%$ higher than the cost of living in MDC. The median child care worker's wage in MA is approximately 10\% higher in MA than in MDC (\$8.59 per hour in MA and \$7.79 per hour in MDC).
} 


\section{movement is often observed when a regulatory agency sets a price ceiling. \\ * FINDING: In both MA \& MDC, unsubsidized providers charge a wider range of prices for the care of infants and toddlers than subsidized providers. The range of prices charged by providers is particularly limited in the subsidized sector in MDC.}

At the beginning of our study (March 1996) and until September 1997, the state weekly provider reimbursement rate for center full-time care of infants in MDC was $\$ 85$. On October 1, 1997, this rate was increased to $\$ 95$. The line in Figure 5 depicts these provider reimbursement rates for the care of infants. Figure 5 also represents, as bars, the medians and $75^{\text {th }}$ percentiles of prices recorded in the MDC R\&R databases for the first quarter of 1996 through the first quarter of 1999. Figure 5 shows that the maximum reimbursement rates for the care of infants was set at the $75^{\text {th }}$ percentile of the prices recorded in the MDC R\&R database prior to October 1997. After October 1997, the maximum reimbursement rates for the care of infants (as well as for one-year-olds) was set above the $75^{\text {th }}$ percentile of the prices recorded in the MDC R\&R database.

Figure 5 shows separately the medians and $75^{\text {th }}$ percentiles of weekly prices charged in MDC for full-time infant care by center providers participating in the subsidized child care program and by those that did not participate. At the beginning of our study period, both the medians and $75^{\text {th }}$ percentiles of prices for providers participating and not participating in the subsidized child care program were virtually the same. Beginning in the third quarter of 1996, the median price of care for subsidized providers increased until it equaled the $75^{\text {th }}$ percentile, while the median price for nonparticipating providers remained unchanged. This type of price movement is often observed when a government or other agency set a price ceiling. The longer the price ceiling is in effect, the more the prices charged by providers who sell to the government or other agency converge to the ceiling.

Note in Figure 5 that at the beginning of the third quarter of 1997, the $75^{\text {th }}$ percentile of weekly infant prices charged by center providers that do not participate in the subsidized child care program begins to rise and exceeds the $75^{\text {th }}$ percentile of prices charged by participating providers. It appears that market forces caused an increase in the prices of care at this time.

In the fourth quarter of 1997, maximum reimbursement rates were raised from $\$ 85$ to $\$ 95$ per week. After this rate increase, the reimbursement rate in MDC exceeded the $75^{\text {th }}$ percentile of prices derived from the R\&R database for both participating and nonparticipating programs. Following this rate increase, the $75^{\text {th }}$ percentile of weekly prices of providers accepting child care subsidies begins to rise in the second quarter of 1998 to a level equal to the $75^{\text {th }}$ percentile of prices charged by providers not accepting children with subsidies.

One additional insight that can be gained from comparing differences between the median prices and $75^{\text {th }}$ percentile of prices for subsidized and unsubsidized care in Figure 5 is that the dispersion (i.e., the difference between the two measures) of prices charged by subsidized providers is much more limited than the dispersion of prices charged by unsubsidized providers. This is also apparent in Tables 2 and 3 by comparing the CVs (coefficients of variation) for subsidized and unsubsidized programs. Only a very limited 
range of prices is observed for providers taking child care subsidies because the prices of providers taking subsidies tend to converge to the government's maximum

reimbursement rate.

Reimbursement rates for infant and toddler care in MA were approximately double those in MDC. This reflects in part the higher market prices in MA (compare the prices in Table 2 with those in Table 3). In the fall of 1998, the reimbursement rate for full-time infant care was $\$ 225$ per week in the Boston area and $\$ 182.50$ per week in the western part of the Commonwealth. For the same period, the reimbursement rate for fulltime toddler care was $\$ 200$ per week in the Boston area and $\$ 167.50$ per week in the western part of the Commonwealth.

Policy Context

In FL as well as in MA, state payments to providers vary depending on the age of the child in care, the type of care, and the area of the state. Federal regulations governing the CCDF child-care subsidy programs require states to set provider reimbursement rates at levels that offer "equal access" to children with child-care subsidies. According to regulations, states must justify that their reimbursement rates provide equal access by referencing a "market-rate" survey that is no more than two-years old. Reimbursement rates set at the $75^{\text {th }}$ percentile of the local market price are presumed to provide equal access.

FL and MA have taken quite different approaches to setting provider reimbursement rates. In FL, the child-care law places the Department of Children \& Families (DCF) in charge of establishing procedures to reimburse providers participating in the subsidized child-care program at the prevailing market rate for child-care services. "Prevailing market rate," according to FL law, means "the annually determined $75^{\text {th }}$ percentile of a reasonable frequency distribution of market rates in a predetermined geographic market at which licensed child-care providers charge a person for child care services." However, provider reimbursement rates cannot exceed the private pay rate a provider charges.

To comply with the law, DCF in FL contracts with the central agencies that manage the subsidized child care program and provide local R\&R services to survey all providers in all areas of the state in the spring of each year. The survey the R\&Rs conduct serves the dual purpose of updating the R\&R provider databases throughout the state and providing information on local market prices. In general, R\&Rs collect "list prices" not market prices. As can be seen in Figure 5, our analysis of the R\&R database in MDC does not seem to coincide with the analysis of the market rate survey after October 1997.

During the period of our study, MA took a different approach to setting reimbursement rates. Periodically, MA hired an outside contractor to survey providers to determine the "arms-length" market price providers charged for care. In contrast to using $\mathrm{R} \& \mathrm{R}$ data, this approach obtains prices for care that is actually purchased (not list prices) and requires that the care be unsubsidized and that the buyer and seller be "unrelated." The Office of Child Care Services (OCCS) in MA uses the market rate survey to substantiate a request to the Legislature for an increase in provider reimbursement rates. On July 1, 1996, the MA Legislature approved reimbursement rates set at the $55^{\text {th }}$ percentile of the local market price of care, determined by a 1994 market rate survey. The Legislature increased reimbursement rates again in September 1998.

The CCDF regulations and state policies create an interesting connection between market prices and provider reimbursement rates. The connection is tightest when states 
conduct annual surveys and set rates based on such surveys. ${ }^{21}$ Under this type of reimbursement rate system, reimbursement rates can only increase when the providers that do not take subsidies raise their prices. The ability of unsubsidized providers to raise prices, of course, depends upon local market conditions.

$>$ HYPOTHESIS: Provider reimbursement rates set on the basis of market prices that do not cover the cost of quality care will not allow for improvements in the quality of care.

Supporting Information: In MDC, reimbursement rates generally have been set at or above the $75^{\text {th }}$ percentile of prices in the R\&R database. In MA, reimbursement rates throughout the study period have been set below the $75^{\text {th }}$ percentile of the local market price of child care. Yet, the quality of care in Massachusetts (as measured by accreditation rates), particularly in the subsidized sector, is quite high, while quality of care in MDC (as measured by accreditation rates) is quite low.

* FINDING: The prices paid for the weekly full-time center care of infants and one-year-olds in MDC are less than 10\% apart, even though the labor costs to provide infant care, given FL's minimum caregiver-to-child ratio requirements, should be about $50 \%$ higher than the labor costs to provide care for one-yearolds.

* FINDING: The prices paid for the weekly full-time center care of infants in MA are approximately $12 \%$ more than prices paid for toddler care, even though the labor costs to provide infant care, given MA's minimum caregiver-to-child ratio requirements, should be about 32\% higher than the labor costs to provide care for one-year-olds.

* FINDING: The prices paid for the weekly full-time center care of infants and two-year-olds in MDC are at most 32\% apart, even though the labor costs to provide infant care, given FL's minimum caregiver-to-child ratio requirements, should be about $175 \%$ higher than the labor costs to provide care for two-yearolds.

* FINDING: These price ratios suggest that centers that comply with the state-promulgated minimum standards must be subsidizing their infant care using funds from sources other than the prices paid by parents for the care of their infants or state reimbursements for such care.

As noted earlier, the required minimum caregiver-to-child ratios in Florida imply a cost of labor to provide care for infants that is $50 \%$ more than the labor costs associated with providing care for one-year-olds and $175 \%$ more than the labor costs of care for two-year-olds. In MA, minimum caregiver-to-child ratio requirements imply that the

${ }^{21}$ The Florida system appears to have this type of system, but Figure 5 suggests that the system is not followed rigorously. 
labor costs of providing infant care that meets the minimum standards are $32 \%$ higher than the labor costs associated with providing toddler care.

Figure 6 gives the ratio of the median weekly full-time price of infant care to twoyear-old care for centers participating and not participating in the subsidized child care program in MDC. It also provides the ratio of the full-time weekly provider reimbursement rate for the care of infants to the rate for the care of two-year olds. Note that unsubsidized providers charge $20 \%$ to $30 \%$ more to care for infants than to care for two-year olds. This price differential, however, does not cover the labor cost differential (175\%) implied by FL's minimum ratio requirements. The reimbursement rate paid by the state to providers for the care of infants also is only $8-12 \%$ higher than the reimbursement rate for two-year-olds. This is strong evidence that the costs of providing infant care that is in compliance with state-imposed standards is not covered by either the prices parents or the state pay. Providers providing infant care must be subsidizing the provision of such care from other sources. Anecdotal evidence indicates that many providers subsidize their infant and toddler programs by charging prices that exceed costs for the care of 3-4 year-olds and school-age children.

The situation in MA, while not as stark, also indicates that centers must be using other sources to subsidize the infant care they provide. As can be seen by comparing the price of infant and toddler care in Table 2, the price of infant care in MA is only approximately $12 \%$ higher than the price of toddler care. MA provider reimbursement rates for infant care are $12.5 \%$ higher than the state's reimbursement rates for toddlers in Boston and $9 \%$ higher in the western part of the state. Yet, minimum standards imply labor costs that are $32 \%$ higher.

To further examine the relationship of costs to prices for infant care, consider the implied costs of meeting minimum caregiver-to-child standards. We estimate that during the period of our study a provider would have to charge $\$ 129$ per week for full-time infant care in FL and $\$ 190$ in MA to cover the costs of providing care that meets minimum caregiver-to-child standards. ${ }^{22}$ As can be seen in Figure 5, neither prices nor reimbursement rates ever exceed $\$ 95$ per week in MDC during the period of our study. The conclusion is that in MDC providers are not being paid enough either by parents or by the state to cover the costs of meeting state-imposed standards. By way of contrast, as can be seen in Table 3, the price of infant care in MA is sufficient to cover the cost of state-imposed minimum caregiver-to-child standards. We do not know whether or not the MA prices are sufficient to meet other state standards (e.g., group size requirements).

The fact that reimbursement rates often do not meet the costs of providing infant and toddler care is one explanation for the slow expansion of infant and toddler care during welfare reform.

\section{$>$ HYPOTHESIS: The relative prices for full-time center care of infants are generally not set at levels that reflect stringent, state- set minimum caregiver-to-child standards for infant care.}

${ }^{22}$ To obtain these numbers, we assumed that staff costs are approximately $75 \%$ of the total costs of providing care, with the remaining $25 \%$ of the cost of care being attributable to space and other facility costs. We also assumed the median child care worker wages, $\$ 7.79$ hour in FL and \$8.59 in MA (see Lemke, et al, 2001 and Queralt, Witte, \& Griesinger, 2000) and a fifty-hour work week. 


\section{HYPOTHESIS: In some areas, neither center prices nor state reimbursement rates cover costs of providing infant care that meets state minimum caregiver-to-child ratio requirements.}

\section{CONCLUSIONS}

We provide descriptive evidence from MDC in FL and from five representative areas in MA that government policies governing welfare reform, the child-care subsidy system, and minimum-standards regulations have had considerable influence on the availability, price, and quality of infant and toddler care as welfare reform progressed from 1996 to 2000. We suspect that the markedly different socio-cultural settings in MDC and MA also have had some influence on the very different situations for infant and toddler care in MDC and MA. ${ }^{23}$

Our data suggest that child-care regulations, market prices, and provider reimbursements in MDC are not in synchrony. Specifically, the prices charged by providers in MDC for the care of infants and the reimbursements providers receive from the state for infant care do not appear to be sufficient to cover the costs of providing infant care that meets the state-imposed minimum standards. This is different from the situation we observe in the five areas of MA we studied, where prices, reimbursements, and regulations are more closely aligned.

Given the current caregiver-to-child ratio requirements for the care of infants and toddlers in FL and MA, we compute that, during the period of our study, a center-based provider would have to charge $\$ 129$ per week for full-time infant care in FL and $\$ 190$ in MA to cover the costs of providing care meeting the minimum ratio requirements. We find that the vast majority of center providers in MDC charged less than $\$ 100$ per week for infant care. In addition, the state-set reimbursements paid to centers in MDC for providing full-time infant care never exceeded $\$ 95$ per week during the period of the study. These prices and reimbursements in MDC were not sufficient to cover the costs of providing infant care that met the high regulatory standards. In contrast, during the same period, we find that MA market prices and provider reimbursement rates for the full-time center care of infants were sufficient to cover the costs of providing care in compliance with the state-imposed caregiver-to-child ratios.

We find that prices of infant and toddler care in MDC are strikingly lower than in MA, even after adjusting for the higher cost of living and the more stringent regulatory environment in MA. We suspect, and provide some evidence, that this marked difference reflects, at least in part, lower average quality of infant and toddler care in MDC than in MA. This is worrisome, given the large numbers of low-income infants and toddlers in formal child care in MDC.

In recent years, MDC has seen rapid increases in the number of infants and toddlers receiving child care subsidies. FL's stringent, work-first welfare reform requires cash assistance recipients to be active when their youngest child is three-months-old. This has led to very rapid rates of increase in the number of low-income infants and toddlers in formal child care settings. The increase in the number of infants and toddlers

\footnotetext{
${ }^{23}$ Mindful of the many factors that affect the child care and early education situation in MDC, the Miami-Dade School Readiness Coalition launched a campaign in the Fall of 2001 to educate parents about the importance of early care and education.
} 
in care became particularly striking after September 1998, when cash assistance recipients began to be removed from the rolls because of time limits. MA's less stringent welfare reform, which requires that cash assistance recipients be active when their youngest child is six years old, has been associated with a rate of increase in the number of infants and toddlers in care that is very much lower than the rate of increase experienced in FL. For example, during our study period the number of infants in care increased by $150 \%$ in MDC and by only $10 \%$ in MA.

In MDC, enrollments at facilities with infant and toddler programs that accept child care subsidies increased moderately during the period of our study, while enrollments at providers that did not take children with subsidies declined. We suggest that the fact that the growth in the full-time enrollment of infants and toddlers at subsidized facilities has been far less dramatic than the increase in the number of child care subsidies issued for infant and toddler care may be indicative of a displacement of infants and toddlers from unsubsidized families by those with child-care subsidies. This scenario seems particularly likely given that, during the period of our study, payments to providers accepting child care subsidies exceeded the median prices charged by providers that did not participate in the subsidized child care program.

One fundamental difference in the formal care of infants and toddlers in MDC as compared to MA is that in MDC care is much more likely to take place at child care centers and much less likely to take place at family child care homes. There are a number of possible explanations for this difference. We suspect that the difference can be explained by some combination of a more pronounced racial and ethnic diversity, higher poverty levels, and a much larger unlicensed, family child care underground economy in MDC than in MA.

The measures of quality of infant care we use in this study are limited, although more extensive than those used in many other large-scale studies that use administrative data. In terms of education and training, we find that the CDA credential is prominent in FL, in part because of regulatory requirements, but it is not very important in MA. In MDC in the period surrounding welfare reform, we find evidence of a widening range of educational attainment among the staff at centers with infant and toddler programs that participate in the subsidized child care program. Specifically, in the course of welfare reform, the proportion of center staff with less than a high school education at subsidized centers increased, at the same time that the proportion of staff with AA and BA degrees also increased. Observational assessments of the quality of infant and toddler programs at centers participating in the subsidized child care program in MDC indicate that the proportion of low-quality infant and toddler programs has approximately doubled (from $5 \%$ of programs in 1996 to $11 \%$ of programs in 1999) during the course of welfare reform.

The level of accreditation of centers with infant and toddler programs in MDC (less than 2\% during the period of our study) is distressingly low. By way of contrast, over $30 \%$ of centers with infant and toddler programs that take vouchers in MA are nationally accredited and between $20 \%$ and $25 \%$ of those that do not take vouchers also are accredited. The low level of accreditation in MDC exists despite the fact that, under FL's Gold Seal program, subsidized providers can receive up to a $20 \%$ increase in reimbursements if they become accredited. By way of contrast, the MA subsidized child care program does not offer higher reimbursements to providers with accreditation. 


\section{Figure 1}

\section{Infant Enrollment in Subsidized Child Care}

By Program

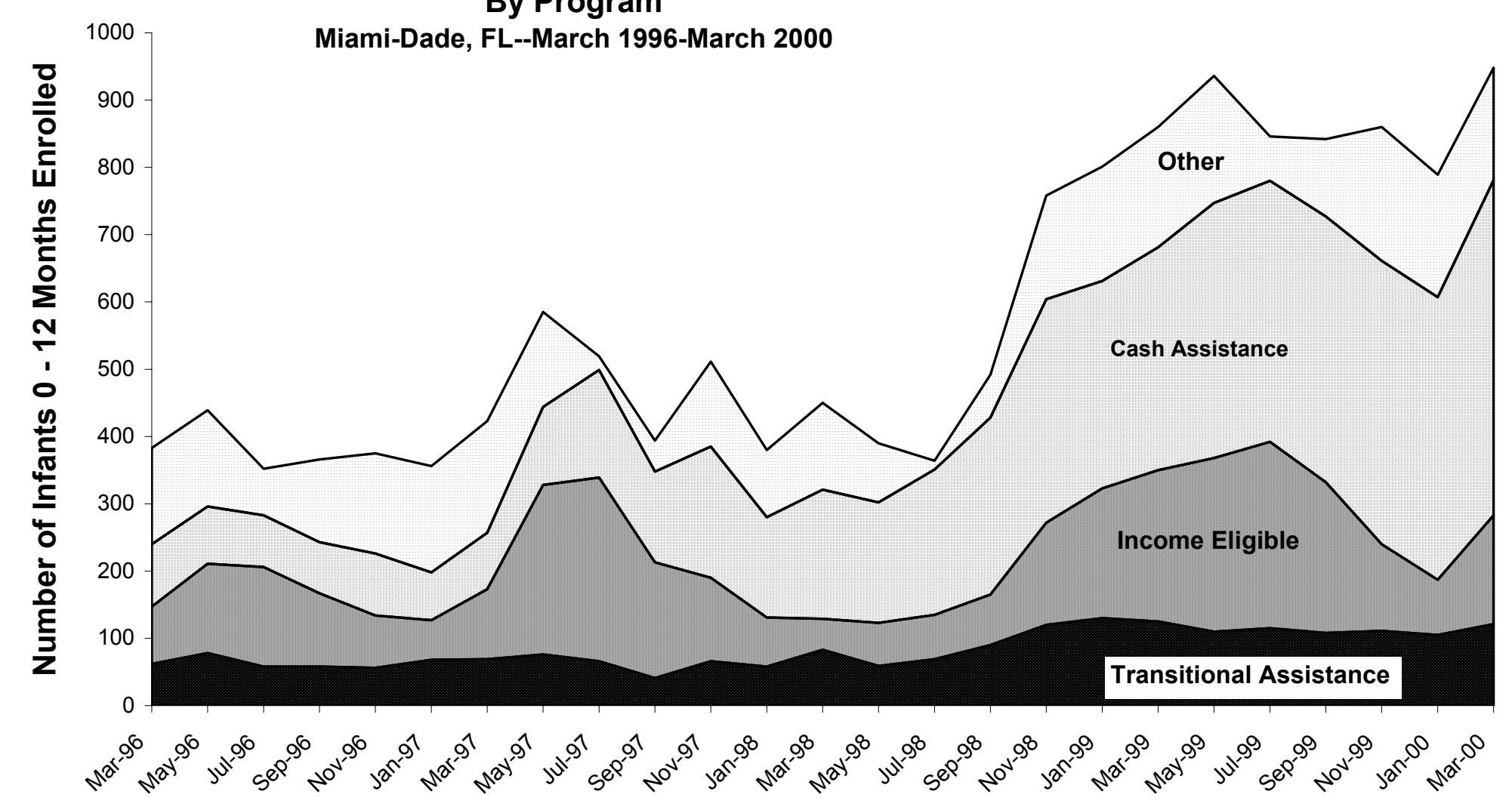


Figure 2

Providers of Serving Infants

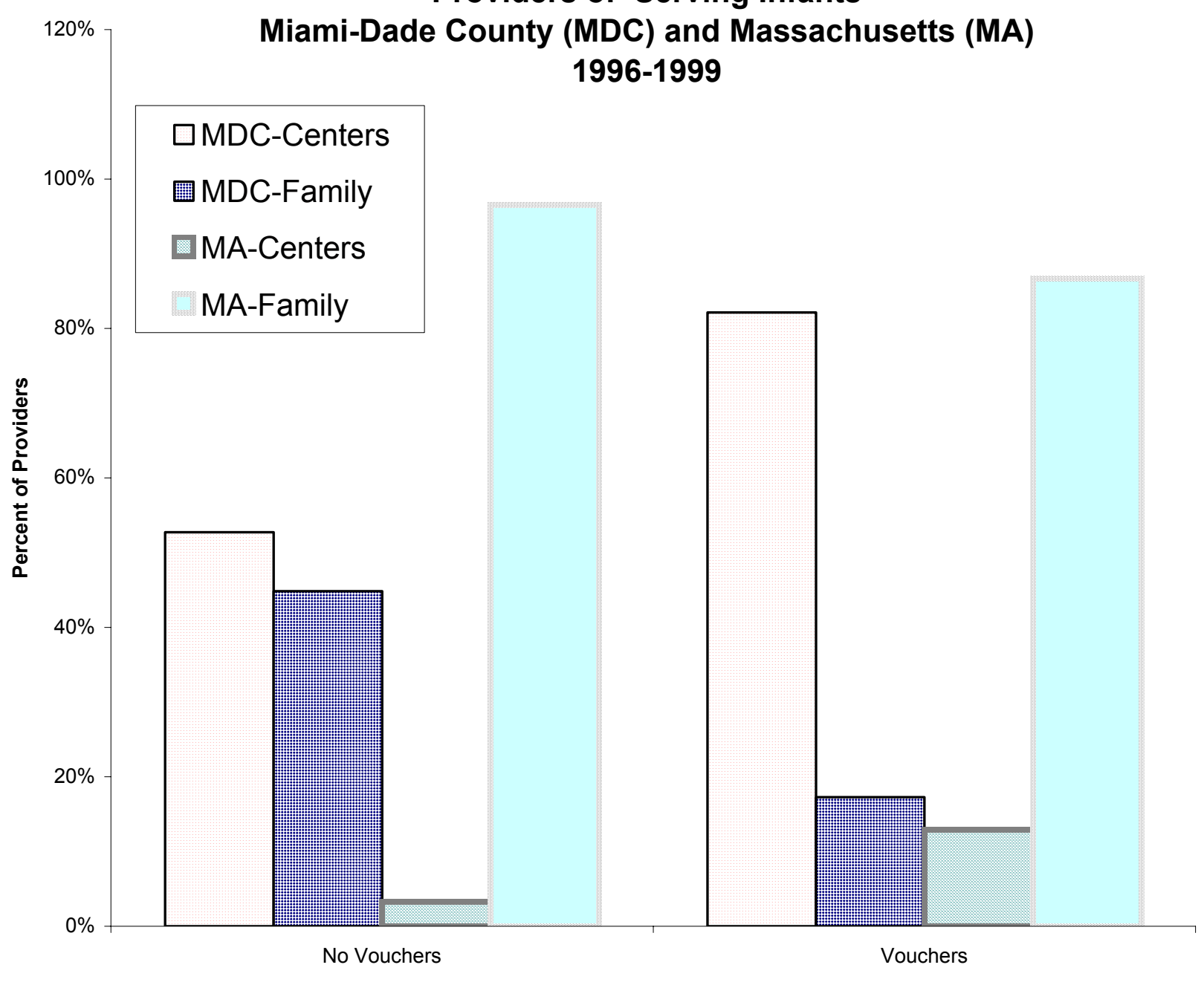




\section{Figure 3}

Providers With Infant Programs Capacities, Enrollment and Vacancies Miami-Dade County, FL

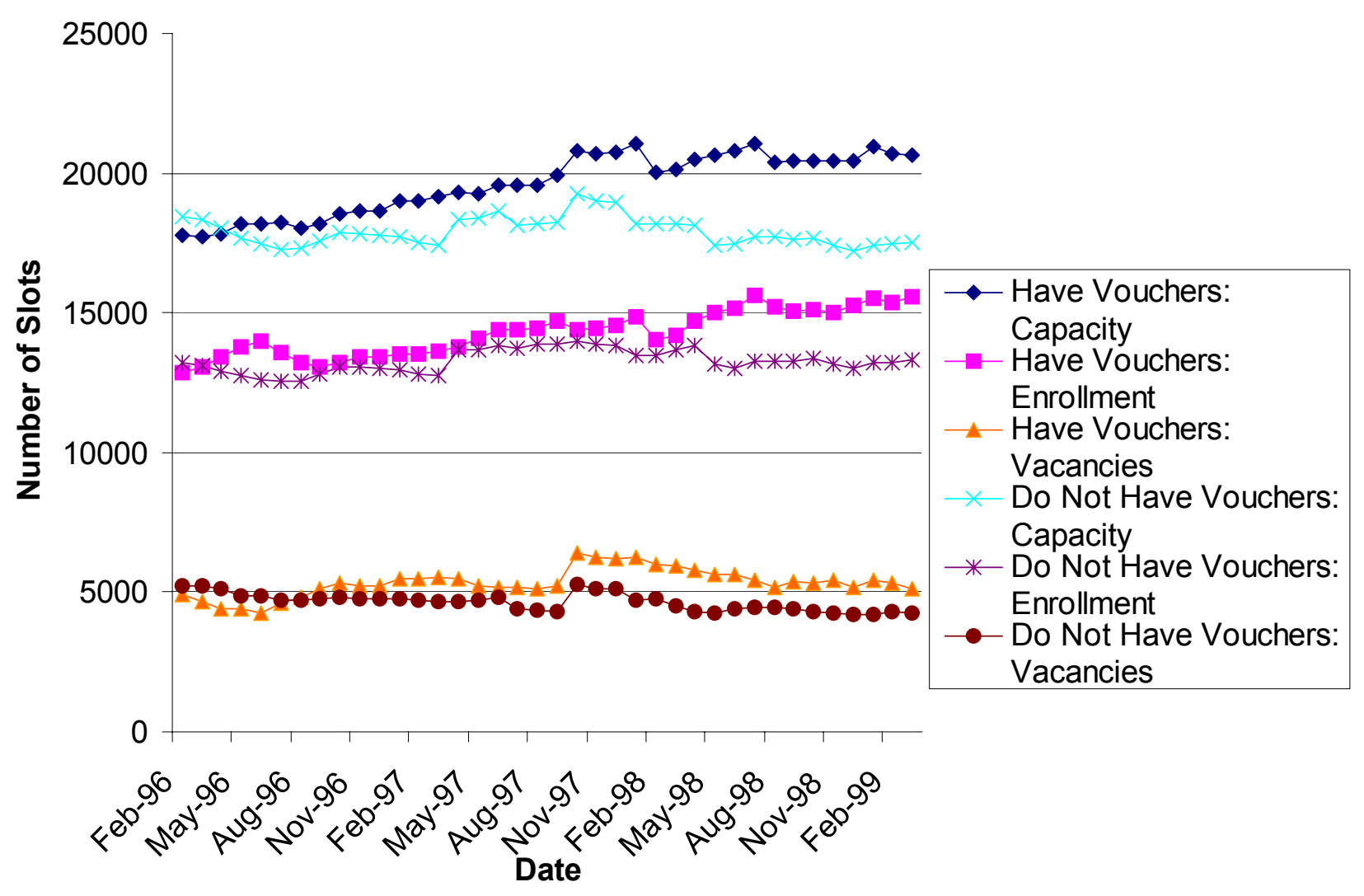




\section{Figure 4}

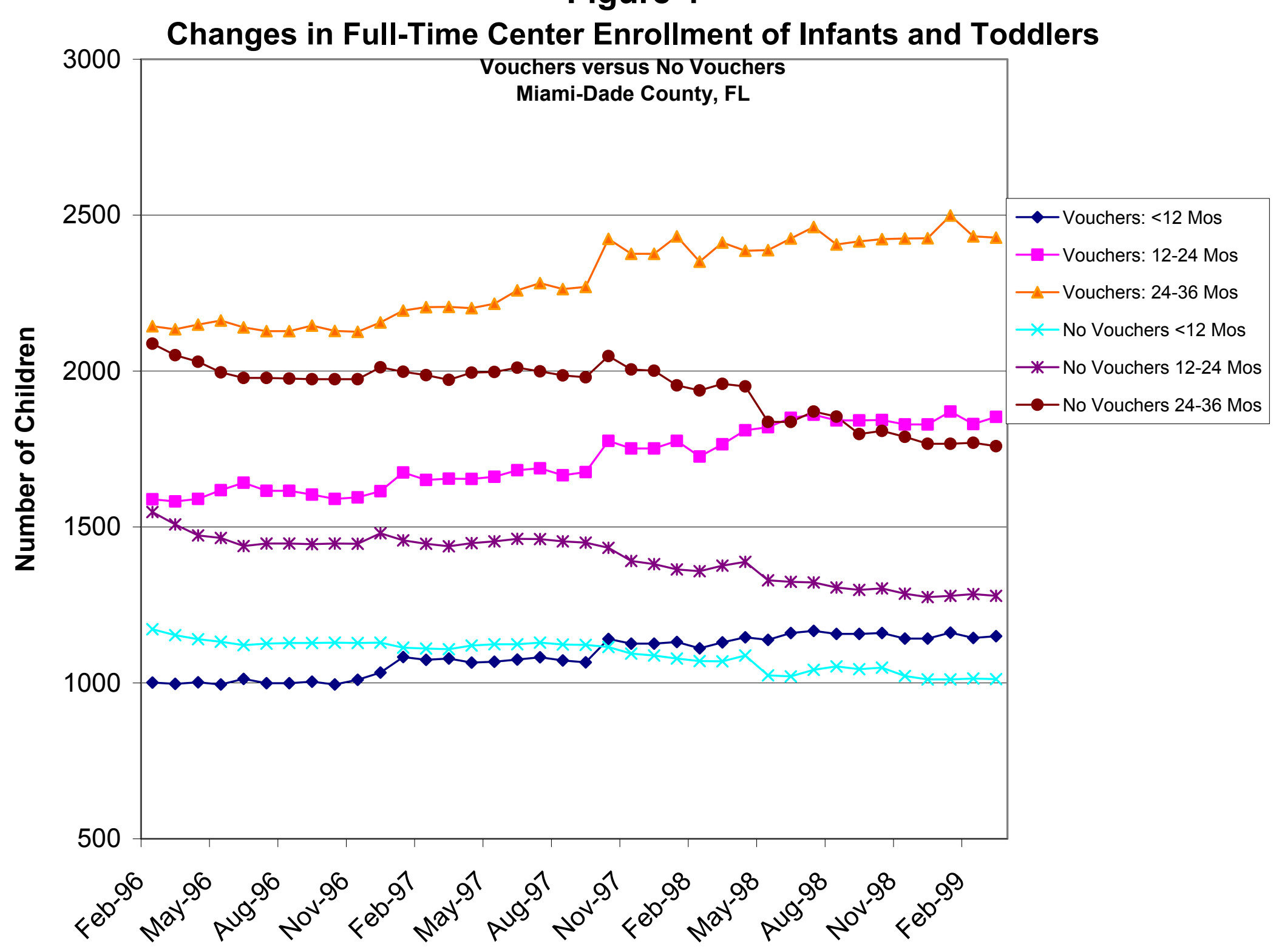




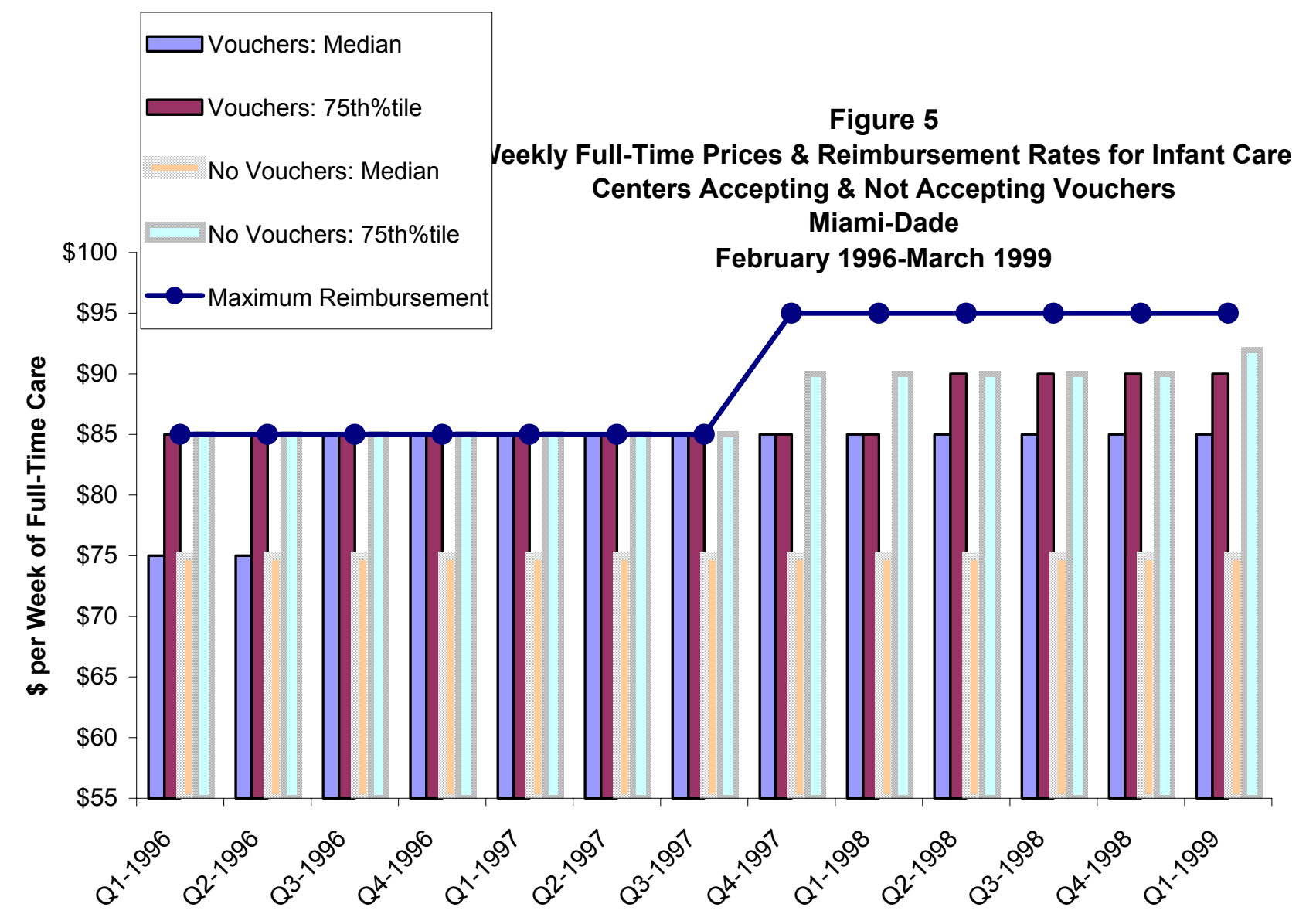


Figure 6

Relative Prices of Center Care for Infants and Two-Year-Olds

Ratio Median Weekly Full-Time Price of Infant Care to Two-Year-Old Care

Miami-Dade County, FL

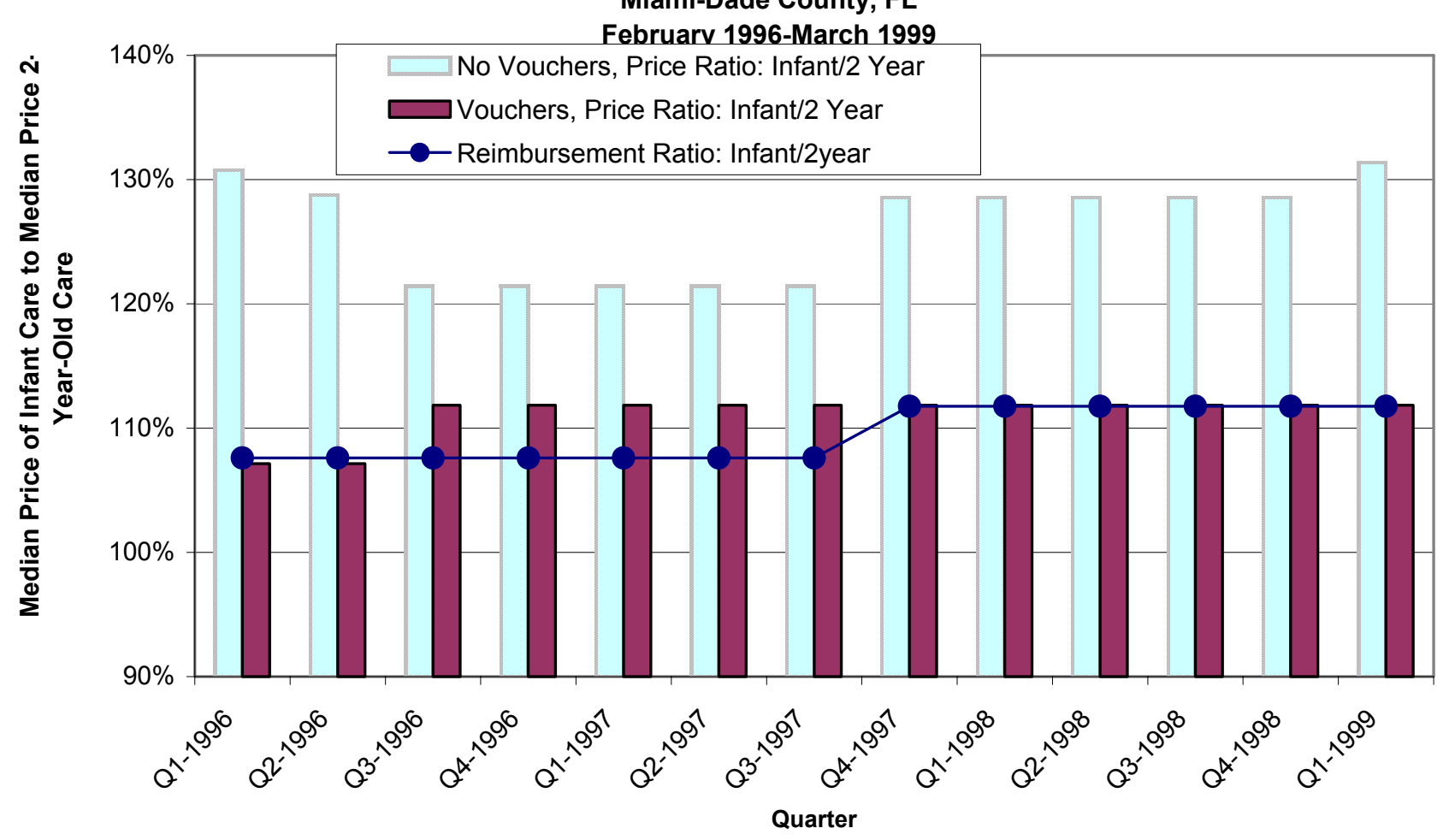




\begin{tabular}{|c|c|c|c|c|c|c|}
\hline \multicolumn{7}{|c|}{$\begin{array}{l}\text { Table } 1 \\
\text { Vouchers for Infants by Type of Provider in Massachusetts } \\
\text { using three Monthly Billing Files for 1997, } 1998 \text { and } 1999\end{array}$} \\
\hline \multirow[b]{2}{*}{ Type of Provider } & \multicolumn{2}{|c|}{1997} & \multicolumn{2}{|c|}{1998} & \multicolumn{2}{|c|}{1999} \\
\hline & Frequency & Percent & Frequency & Percent & Frequency & Percent \\
\hline Centers & 503 & 43.5 & 396 & 31.1 & 430 & 33.7 \\
\hline FCC System & 223 & 19.3 & 256 & 20.1 & 255 & 20.0 \\
\hline FCC Independent & 118 & 10.2 & 173 & 13.6 & 156 & 12.2 \\
\hline Informal & 313 & 27.1 & 448 & 35.2 & 436 & 34.1 \\
\hline Total & 1157 & 100.0 & 1273 & 100.0 & 1277 & 100.0 \\
\hline
\end{tabular}




\begin{tabular}{llllllllll}
\hline \multicolumn{10}{c}{ Table $\mathbf{2}$} \\
Weekly Non-Zero Prices of Center-Based Child Care and Early Childhood Education \\
Five Representative Areas of Massachusetts--1997-1999
\end{tabular}

*The non-subsidized market prices are the non-zero prices charged by providers other than FCC's, head start, public schools, nonpublic schools and those centers participating in the subsidized child care program.

\begin{tabular}{lcccccccccc}
\hline \multicolumn{1}{c}{ Table 3} \\
Weekly Non-Zero Prices of Center-Based Child Care and Early Childhood Education \\
Miami-Dade County--1997-1999
\end{tabular}

*The non-subsidized market prices are the non-zero prices charged by providers other than FCC's, head start, public schools, nonpublic schools and those centers participating in the subsidized child care program. 


\section{References}

Bennett, N.G. \& Hsien-Hen Lu. (2000). Child Poverty in the States: Levels and Trends from 1979 to 1998. Childhood Poverty Research Brief 2. New York: National Center for Children in Poverty. Available at:

http://cpmcnet.columbia.edu/dept/nccp/cprb2txt.html.

Lemke, R.J., Witte, A.D., Queralt, M., \& Witt, R. (March 2000). Child Care and the Welfare to Work Transition. Working Paper 7583. Cambridge, MA: National Bureau of Economic Research. Available at: http://www.nber.org/papers/w7583

National Research Council and Institute of Medicine (2000). From Neurons to Neighborhoods: The Science of Early Childhood Development. Committee on Integrating the Science of Early Childhood Development. Jack P. Shonkoff and Deborah A. Phillips, eds. Board of Children, Youth, and Families, Commission on Behavioral and Social Sciences and Education. Washington, DC: National Academy Press.

Marshall, N., et al. (1988). The Economics of Child Care in Massachusetts. Boston: Massachusetts Department of Human Services.

Queralt, M,. Witte, A., and Griesinger, H. (2000a). "Championing our Children": Changes in the Quality, Price and Availability of Child Care in the Welfare Reform Era, Working Paper \#2000-07. Wellesley, MA: Department of Economics, Wellesley College. Available at: http://www.wellesley.edu/Economics/wkpapers/index.html.

Queralt, M., Witte, A., and Griesinger, H. (2000b). Changing Policies, Changing Impacts: Employment and Earnings of Child-Care Subsidy Recipients in the Era of Welfare Reform. Social Service Review, 74(4): 588-619.

Vandell, D.L. and Wolfe, B. (May, 2000). Child Care Quality: Does It Matter and Does It Need to Be Improved? Washington, DC: Office of the Assistant Secretary for Planning and Evaluation. U.S. Department of Health and Human Services. Available on the Internet at : http://aspe.hhs.gov/hsp/ccquality00/ccqual.htm.

Witt, Robert; Queralt, Magaly; \& Witte, Ann (2000). Changes in the Availability, Quality and Price of Child Care Services in Massachusetts between 1997 and 1999. Wellesley College Department of Economics Working paper 2000-12. Available at: http://www.wellesley.edu/Economics/wkpapers/index.html. 